\title{
Feasibility and safety of porcine Descemet's membrane as a carrier for generating tissue-engineered corneal endothelium
}

\author{
YU-MEI DIAO and JING HONG \\ Department of Ophthalmology, Peking University Third Hospital, Beijing 100191, P.R. China
}

Received February 28, 2014; Accepted December 2, 2014

DOI: $10.3892 / \mathrm{mmr} .2015 .3665$

\begin{abstract}
The aim of this study was to evaluate the feasibility and safety of porcine Descemet's membrane (DM) as a carrier for the generation of tissue-engineered corneal endothelium by analyzing porcine endogenous retroviruses (PERVs) and the $\alpha$-gal epitope. The morphology of porcine and human DM was observed by hematoxylin and eosin staining and scanning electron microscopy. Immunohistochemical staining was used to investigate the location of $\alpha$-gal epitopes on porcine DM used for xenotransplantation. The porcine DM was treated with ethylene glycol diglycidyl ether (EDGE) for 2 weeks, and then the PERV gene sequences in porcine DM and DM-EDGE were detected by polymerase chain reaction (PCR) and real-time PCR, respectively. The porcine DM had tight basement membrane morphology, which was similar to human DM in terms of thickness. No positive immunohistochemical staining of the $\alpha$-gal epitope was detected in porcine DM. PERV expression of pol, gag, env-A and $e n v-B$ was noted in porcine DM, but in DM-EDGE it was completely degraded. Based on structural, immunological and etiological studies, porcine DM may be an ideal and viable carrier for the generation of tissue-engineered corneal endothelium.
\end{abstract}

\section{Introduction}

The corneal endothelium exhibits no regenerative capacity, therefore decompensation of the corneal endothelium induced by a decreased cell density will fail to maintain corneal hydration, thickness and transparency (1-3). Once irreversible decompensation of the corneal endothelium occurs, corneal transplantation is required to restore visual function.

Currently, endothelial keratoplasty is the most frequently used surgical treatment for corneal endothelial diseases $(4,5)$.

Correspondence to: Dr Jing Hong, Department of Ophthalmology, Peking University Third Hospital, 49 North Garden Road, Beijing 100191, P.R. China

E-mail: hongjing1964@163.com

Key words: tissue-engineered corneal endothelium, carrier, porcine Descemet's membrane
However, low endothelial cell count, possible age-related diseases, cultural, logistical and technical difficulties, long postmortem time and severe damage occurring during the handling of fragile donor corneas affect the availability of donor tissues $(6,7)$. These challenges contribute to the global shortage of suitable transplant-grade corneal tissues.

Corneal tissue engineering has recently emerged as a promising option to overcome these challenges. In addition to collagen, gelatin membranes and amniotic membrane, Descemet's membrane (DM) is one of the most effective choices as a natural scaffold for tissue-engineered endothelium, although worldwide demand for human donor corneas far exceeds supply (8). Compared with other matrices, the porcine cornea appears particularly attractive as a possible scaffold due to its similar anatomic and biomechanical parameters to the human cornea (9-11); in addition, it shows great promise in providing a virtually limitless supply of cells, tissues and organs for a variety of therapeutic procedures.

There are two main obstacles, however, preventing pig-to-human xenotransplantation. One is the immunological hyperacute or delayed rejections induced by xenotransplantation $\alpha$-gal epitopes (12-15), which are expressed in the cell membranes of all mammals except those of humans and Old World monkeys. The other is the transmission of porcine micro-organisms, particularly the infection of porcine endogenous retroviruses (PERVs) to the human xenotransplantation recipient $(16,17)$. These issues must be resolved before xenotransplantation becomes a clinical possibility.

At present, there are no studies that describe $\alpha$-gal and PERVs in porcine DM for corneal transplantation. The purpose of this study was to evaluate the safety and feasibility of porcine DM as a carrier for generating tissue-engineered corneal endothelium.

\section{Materials and methods}

Animals. Fresh porcine corneas were obtained from a local slaughter house. Human corneas were obtained from the Peking University Eye Bank, originating from three females and three males aged 72-83 years old. All experiments adhered to the ARVO Statement for the Use of Animals in Ophthalmic and Vision Research and the Declaration of Helsinki. The study was approved by the Ethics Committee of Peking University Third Hospital, China. All reagents were obtained from Sigma-Aldrich (St. Louis, MO, USA) unless otherwise stated. 
Table I. Weights of various porcine tissues.

\begin{tabular}{lcccc}
\hline Weight (g)/tissue & Sample 1 & Sample 2 & Sample 3 & Mean \pm SD \\
\hline Full-thickness cornea & 0.0227 & 0.0215 & 0.0195 & $0.0212 \pm 0.0016^{\mathrm{a}}$ \\
Epithelium & 0.0229 & 0.0214 & 0.0191 & $0.0211 \pm 0.0019^{\mathrm{a}}$ \\
Stroma & 0.0229 & 0.0219 & 0.0195 & $0.0214 \pm 0.0017^{\mathrm{a}}$ \\
Descemet's membrane & 0.0227 & 0.0218 & 0.0193 & $0.0213 \pm 0.0018^{\mathrm{a}}$ \\
Descemet's membrane and epithelium & 0.0227 & 0.0218 & 0.0194 & $0.0213 \pm 0.0017^{\mathrm{a}}$ \\
Iris & 0.0224 & 0.0219 & 0.0195 & $0.0213 \pm 0.0016^{\mathrm{a}}$ \\
Aqueous humor & 0.0226 & 0.0211 & 0.0197 & $0.0211 \pm 0.0215^{\mathrm{a}}$
\end{tabular}

There were no significant differences in the weights of various parts of the porcine cornea ( ${ }^{\mathrm{a}} \mathrm{P}>0.05 \mathrm{vs}$. the different parts of the porcine tissues).

Separation of different sections of the porcine cornea. Corneal epithelia were scraped by a microkeratome. To remove the corneal endothelial cells, each DM was first incubated with $0.02 \%$ ethylenediaminetetraacetic acid (EDTA) at $37^{\circ} \mathrm{C}$ for $45 \mathrm{~min}$. A cell scraper was used to remove the corneal endothelial cells from the DM (the denuded DM). A 30-gauge needle bent bevel-up was attached to a 1-ml syringe filled with air and was inserted into the posterior stroma with the entry point located just outside of the Schwalbe line. The needle was advanced between the stroma and the DM. Air was gently injected, causing corneal emphysema. The rapidly formed air bubble coalesced into a large bubble (Fig. 1), thus detaching the DM from the posterior stoma (18).

Histological examination of porcine and human DMs. For hematoxylin and eosin (H\&E) staining, six human and six porcine corneas were fixed in $4 \%$ formaldehyde, dehydrated in a series of ethanol solutions and embedded in paraffin. Cross-sections of $4 \mu \mathrm{m}$ were cut, stained with $\mathrm{H} \& \mathrm{E}$ and examined under a light microscope (dm4000B; Leica, Wetzlar, Germany).

Scanning electron microscopy. The denuded porcine DM was fixed in $2.5 \%$ glutaraldehyde in $0.1 \mathrm{M}$ phosphate-buffered saline (PBS), washed three times for $15 \mathrm{~min}$ in PBS, postfixed for $2 \mathrm{~h}$ in $2 \%$ osmium tetroxide and washed three more times in PBS. Following dehydration through a series of graded ethanol solutions $(50,70,80,90,95$ and $100 \%)$, specimens were transferred to hexamethyldisilazane for 2x10 min and allowed to air dry. When dry, the specimens were mounted on aluminum stubs and sputter-coated with gold prior to examination using a scanning electron microscope (JSM-5600; Jeol, Tokyo, Japan).

Immunohistochemical evaluation of the $\alpha$-gal epitope. The location of the $\alpha$-gal epitope in the DM was determined by immunohistochemical staining using paraffin-embedded tissue sections, following the method of Gonzalez-Andrades et al (19). First, paraffin was removed from the tissue sections with xylene, then the samples were rehydrated in water through a graded series of alcohol solutions $(100,95,90,85,80$ and $70 \%$ ) and washed 3 times with PBS for 5 min. Endogenous peroxidase activity was blocked with $3 \%$ hydrogen peroxide (PV-6002, two-step IHC detection reagent; ZSGB-BIO, Beijing, China) for $10 \mathrm{~min}$ at room temperature, and the tissue samples were rinsed three times with PBS for $5 \mathrm{~min}$. The tissue samples were treated with a trypsin solution $(0.125 \%)$ maintained at $37^{\circ} \mathrm{C}$ for $45 \mathrm{~min}$ for antigen retrieval and then washed three times for $5 \mathrm{~min}$ with PBS. The samples were incubated with monoclonal mouse antibody (ALX-801-090-1, clone M86; Alexis Biochemicals, Farmingdale, NY, USA) against the $\alpha$-gal epitope at a 1:100 dilution at $4^{\circ} \mathrm{C}$ overnight. Then, the samples were equilibrated to room temperature. Incubation with secondary antibodies (pv-9002; ZSGB-BIO) was carried out for 45 min using anti-mouse secondary antibodies. After removing the secondary antibody, the slides were washed three times for $5 \mathrm{~min}$ with PBS. Next, the slides were treated with DAB (ZSGB-BIO) as the chromogenic agent for $3 \mathrm{~min}$. Finally, the sections were counterstained with hematoxylin and photographed under a light microscope.

DNA extraction. Genomic DNA was extracted from the samples by following the procedure listed in the genomic DNA extraction kit instructions (catalog no. 51304; Qiagen, Hamburg, Germany). The tissues were weighed three times to verify that they were $\leq 25 \mathrm{mg}$, as per the kit instructions. Details are shown in Table I. The DNA extractions were repeated three times. Extracted genomic DNA concentrations were determined by a NanoDrop 2000c spectrophotometer (Thermo Fisher Scientific, Waltham, MA, USA).

Polymerase chain reaction (PCR). In this process, gag, pol and envelope genes $e n v-A, e n v-B$ and $e n v-C$ were selected as the PERV-specific genes. The previously described primer sequences were as follows (20): gag-F (5'-CCCGATCAGGAG CCCTATATCCTTACGTG-3') and $g a g$-R (5'-CGCAGCGGT AATATCGCGATCTCGT-3') (GenBank: AF038599.1); pol-F (5'-AGCTCCGGGAGGCCTACTC-3') and pol-R (5'-ACA GCCGTTGGTGTGGTCA-3') (GenBank: Y17013.1) (21); $e n v-A$-F (5'-GAGATGGAAAGATTGGCAACAGCG-3') and env-A-R (5'-AGTGATGTTAGGCTCAGTGGGGAC-3') (GenBank: HQ688785.1); env-B-F (5'-AATTCTCCTTTG TCAATTCCGGCCC-3') and $e n v-B$-R (5'-CCAGTACTTTAT CGGGTCCCACTG-3') (GenBank: AY056035.1); and env-C-F (5'-CTGACCTGGATTAGAACTGGAAGC-3') and $e n v-C$-R (5'-GTTATGTTAGAGGATGGTCCTGGTC-3') (GenBank: AY534304.1). The housekeeping gene GAPDH was selected as an internal reference gene using the following primers: GAPDH-F (5'-ACATGGCCTCCAAGGAGTAAGA-3') and 
GAPDH-R (5'-GATCGAGTT GGGGCTGTG ACT-3') (AF_017079.1). A PCR kit was used for this procedure (6210A; Takara, Dalian, China). The PCR mixture included $0.4 \mu \mathrm{l}$ Takara Taq (5 U/ $\mu 1$; Takara), $5 \mu 1$ 10X PCR buffer, $2.5 \mathrm{mM}$ dNTP mixture, 10 ng DNA sample, $1 \mu 1$ PCR forward primer $(20 \mu \mathrm{M})$ and $1 \mu \mathrm{l}$ PCR reverse primer $(20 \mu \mathrm{M})$; finally $\mathrm{dH}_{2} \mathrm{O}$ was added for a total volume of $50 \mu \mathrm{l}$. PCR assays were performed with a PCR system (T-Gradient Thermoblock, serial no. 2009179, Biometra, Göttingen, Germany). DNA templates were amplified with 30 cycles at $94^{\circ} \mathrm{C}$ for $30 \mathrm{sec}$, at $59^{\circ} \mathrm{C}(G A P D H, p o l)$ or $64^{\circ} \mathrm{C}(g a g, e n v-A, e n v-B$ and $e n v-C)$ for $30 \mathrm{sec}$ and at $72^{\circ} \mathrm{C}$ for $1 \mathrm{~min}$. PCR products were separated on a $3 \%$ agarose gel in Tris-acetate-EDTA buffer.

Real-time PCR assay for pol gene sequences. The expression levels of pol (pol-F 5'-AGCTCCGGGAGGCCTACTC-3', pol-R 5'-ACAGCCGTTGGTGTGGTCA-3') (GenBank: Y17013.1) (22) were detected by real-time PCR assays, and a full-thickness cornea was used as a control. The housekeeping gene porcine transferrin receptor $(t f r c)(t f r c$-F 5'-GAGACA GAAACTTTCGAAGC-3', tfrc-R 5'-GAAGTCTGTGGTATC CAATCC-3') (NM_214001.1) (22) was selected as an internal reference gene. This reaction system in a total volume of $20 \mu \mathrm{l}$ using the SYBR Premix Ex Taq ${ }^{\mathrm{TM}}$ kit (DRR420A, Takara) included $10 \mu \mathrm{l}$ SYBR Premix Ex Taq (2X), $0.4 \mu \mathrm{l}$ PCR forward primer, $0.4 \mu 1$ PCR reverse primer, $0.4 \mu 1$ ROX reference dye II

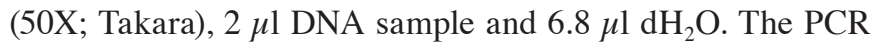
conditions involved initial denaturation at $95^{\circ} \mathrm{C}$ for $30 \mathrm{sec}$ followed by $95^{\circ} \mathrm{C}$ for $5 \mathrm{sec}$ and $59^{\circ} \mathrm{C}$ for $34 \mathrm{sec}$. This process was performed with a 7500 Real-Time PCR system (ABI 7500, Applied Biosystems, Grand Island, NY, USA). The assay was performed in triplicate and repeated three times. The results were analyzed using the $2^{-\Delta \Delta \mathrm{Ct}}$ method of Livak and Schmittgen (23).

Chemical treatment of porcine DM. The porcine DM was chemically stabilized with 5\% ethylene glycol diglycidyl ether (EDGE; CAS: 2224-15-9; Tokyo Chemical Industry Co., Ltd., Tokyo, Japan) solution in phosphate buffer ( $\mathrm{pH}$ 7.46). Twenty samples were incubated at $25^{\circ} \mathrm{C}$ for 2 weeks. The EDGE solution was changed after 1 and 6 days of fixation. Specimens for molecular analysis were collected after 14 days. All samples were rinsed with sterile physiological saline solution for $15 \mathrm{~min}$ to remove residual substances, then they were stored frozen at $-80^{\circ} \mathrm{C}$ for $24 \mathrm{~h}$ until DNA extraction (24).

Statistical analysis. Statistical analyses were performed using SPSS 16.0 statistical software (SPSS Inc., Chicago, IL, USA). A completely randomized design analysis of variance (ANOVA, one-factor ANOVA) was used to evaluate the test data by the Student-Newman-Keuls and least significant difference tests. Experimental data are expressed as the mean \pm standard deviation. $\mathrm{P}<0.05$ was considered to indicate a statistically significant difference.

\section{Results}

Histological examination. As shown in Fig. 2, the histological examination by H\&E staining confirmed that porcine DM was a basal lamina, which was similar to the structure of human

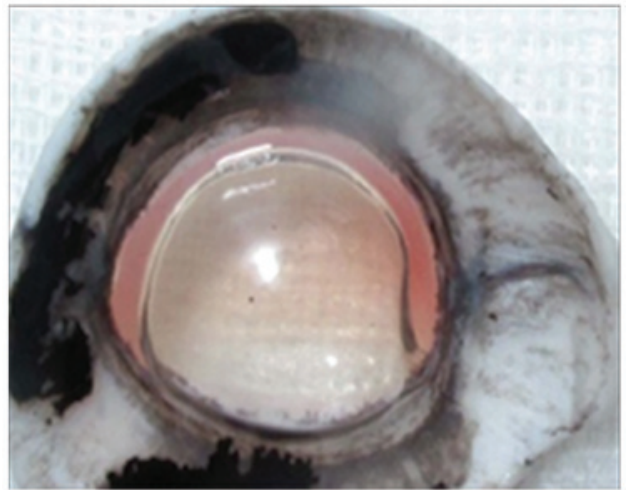

Figure 1. A large bubble induces the detachment of Descemet's membrane from the posterior stroma.

A

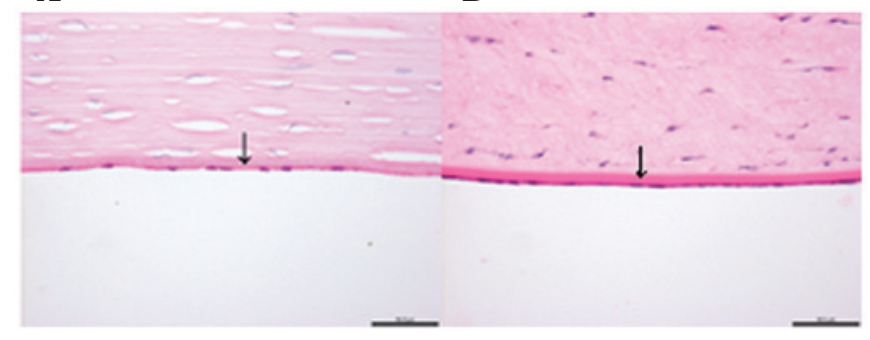

Figure 2. Hematoxylin staining. (A) Human Descemet's membrane (DM) (black arrow); (B) porcine DM (black arrow). The porcine DM structure was similar to that of the human DM. Bar=50.0 $\mu \mathrm{m}(\mathrm{n}=6)$.

$\mathbf{A}$

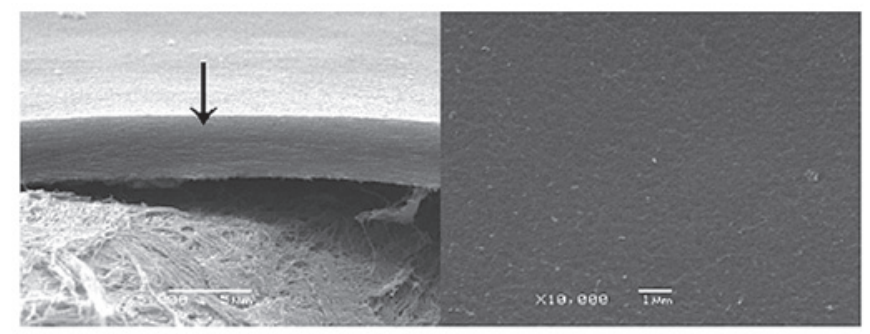

Figure 3. Morphology of denuded porcine Descemet's membrane (DM) under a scanning electronic microscope. (A) The porcine DM was a tight membrane through the longitudinal section. Bar=5 $\mu \mathrm{m}$. (B) No residual cells were observed on the denuded porcine DM. Bar $=1 \mu \mathrm{m}$.

DM. The scanning electron microscope examination further revealed that the porcine DM was a tight membrane through the longitudinal section (Fig. 3A), while no residual corneal endothelial cells were observed on porcine DM following EDTA treatment (Fig. 3B).

Immunohistochemical localization of $\alpha$-gal epitope in porcine cornea. The localization of the $\alpha$-gal epitope in the porcine cornea was detected using immunohistochemical staining. The staining of the $\alpha$-gal epitope in the conjunctiva was used as a positive control, and samples with no primary antibody were used as negative controls. As shown in Fig. 4, positive immunohistochemical localization of the $\alpha$-gal epitope in porcine tissues was identified in conjunctiva and stroma cells, but no positive staining was observed in the porcine DM. 
A

B

C

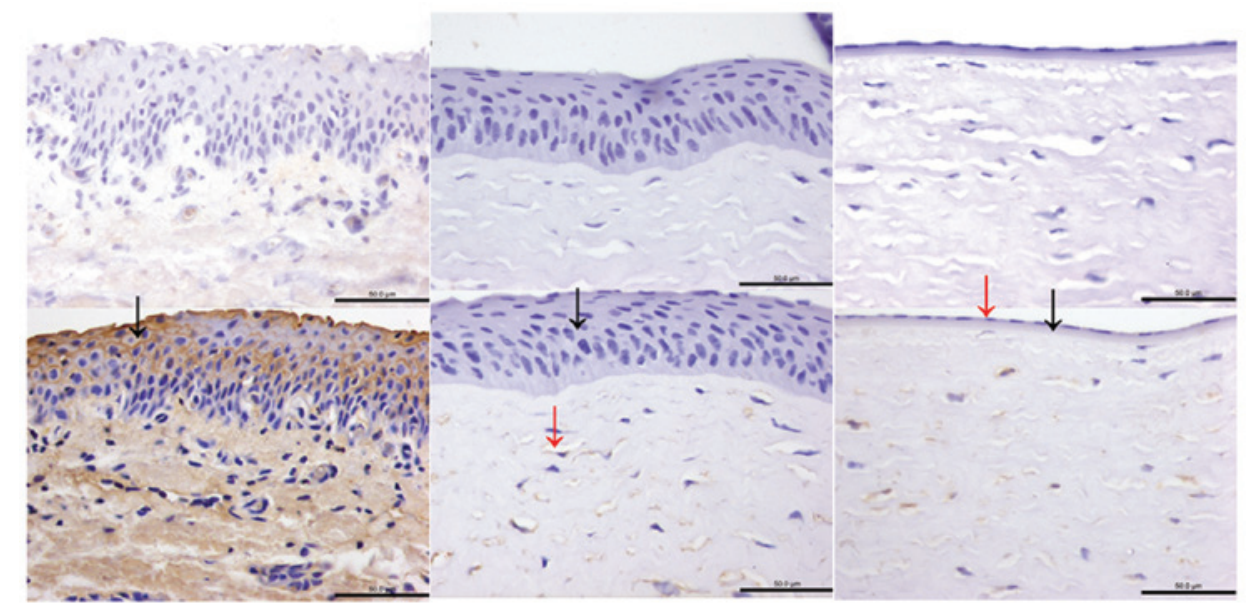

Figure 4. Immunohistochemical localization of $\alpha$-gal epitopes in the porcine cornea. (A) Conjunctiva negative control (upper panel). Expression of the $\alpha$-gal epitope on the conjunctiva is indicated (black arrow, lower panel). (B) Epithelium and stroma negative control (upper panel). Expression of the $\alpha$-gal epitope on the epithelium was negative (black arrow), but it was positive on the stroma (red arrow) (lower panel). (C) Endothelium and Descemet's membrane negative control (upper panel). Expression of the $\alpha$-gal epitope on the endothelium (red arrow) and the Descemet's membrane (black arrow) were negative (lower panel). $\operatorname{Bar}=50.0 \mu \mathrm{m}(\mathrm{n}=6)$.

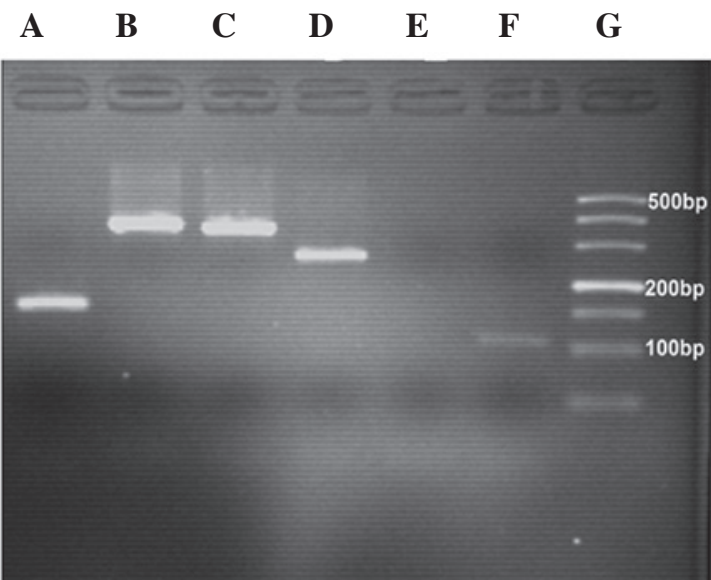

Figure 5. Porcine endogenous retrovirus gene sequence expression in porcine Descemet's membrane. (A) pol, $150 \mathrm{bp}$; (B) gag, $362 \mathrm{bp}$; (C) env-A, $359 \mathrm{bp}$; (D) env-B, 263 bp; (E) env-C, 261 bp; (F) GAPDH, 106 bp; (G) marker.

PERV expression in porcine DM. The PCR results revealed that PERV sequences of $p o l, g a g, e n v-A$ and $e n v-B$ were expressed in normal porcine DM, but env-C was not detected (Fig. 5). In addition, the expression of PERVs was negative in porcine DM-EDGE (Fig. 6). The expression of pol in porcine DM was compared with other corneal tissues using real-time PCR, and no statistical difference was noted $(\mathrm{P}>0.05)$. However, comparing the iris and the aqueous humor, the expression of pol was greater in the iris $(\mathrm{P}<0.01)$. There were no statistically significant differences among the various parts of the porcine cornea (P>0.05; Fig. 7).

\section{Discussion}

Endothelial keratoplasty has been increasingly performed in recent years in patients exhibiting endothelial dysfunctions from surgical trauma (5), corneal endothelial diseases $(4,25)$ or age-related pathologies. Therefore, good-quality corneal
A
B $\mathbf{C}$
D
E $\quad$ F G

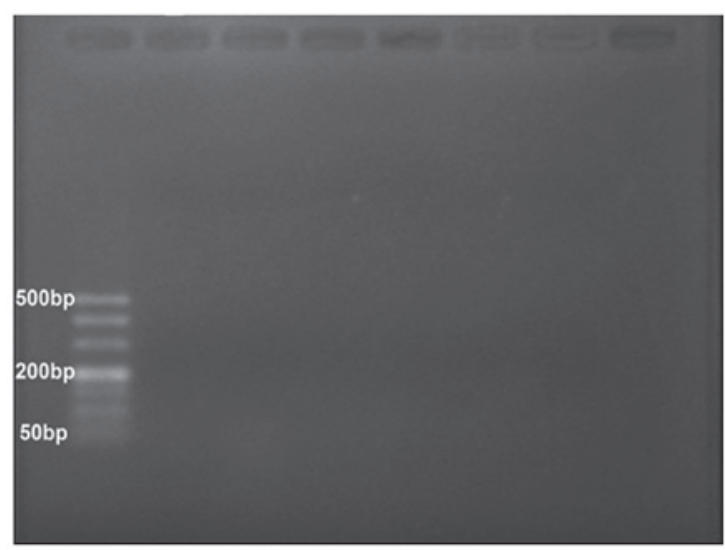

Figure 6. Following treatment with ethylene glycol diglycidyl ether, there was no detectable expression of porcine endogenous retrovirus gene sequences in porcine Descemet's membrane. (A) Marker; (B) pol, 150 bp; (C) gag, 362 bp; (D) env-A, 359 bp; (E) env-B, 263 bp; (F) env-C, 261 bp. (G) GAPDH, 106 bp.

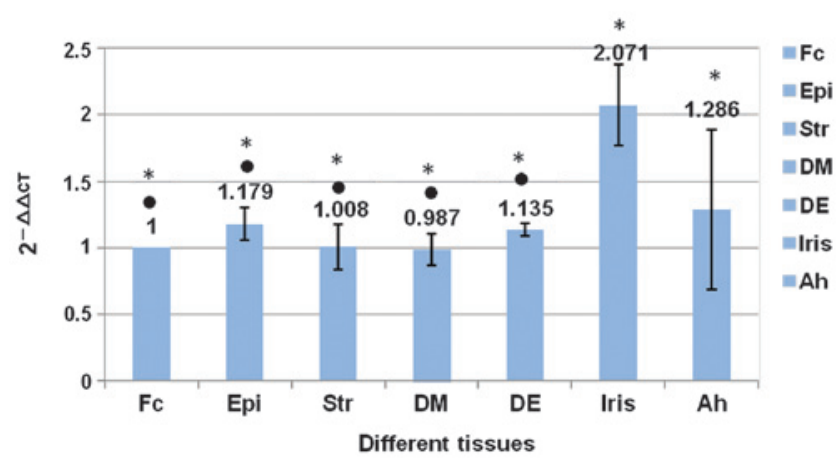

Figure 7. Comparison of pol expression between the porcine DM and other porcine tissues. $\Delta \Delta \mathrm{Ct}=(\Delta \mathrm{CT}$ sample- $\Delta \mathrm{CT}$ control $) . \Delta \mathrm{CT}=$ pol-tfrc. $\mathrm{Fc}$ full-thickness cornea; Epi, epithelium; Str, stroma; DM, Descemet's membrane; DE, Descemet's membrane+endothelium; Ah, aqueous humor. Each error bar represents the $2^{-\Delta \Delta C T}$ standard deviations of $\mathrm{pol}$ from three replicates. The iris had the highest expression of $p o l$ sequences $\left({ }^{*} \mathrm{P}<0.01\right.$ vs. the iris). There were no significant differences in different parts of the porcine cornea $(\bullet P>0.05$ vs. the different parts of the porcine cornea). 
endothelial donors are urgently required. The concept of a tissue-engineered endothelium provides new hope for overcoming these challenges. Seed cells, scaffolds and functional evaluation following transplantation are the main obstacles preventing the use of a tissue-engineered endothelium in human patients. This study was conducted to evaluate the feasibility and safety of porcine DM as a tissue-engineered endothelial scaffold by analyzing PERVs and the $\alpha$-gal epitope. Our results revealed that porcine DM was appropriate as a tissue-engineered endothelial scaffold in terms of its anatomical, immunological and etiological characteristics.

One of the barriers of corneal endothelial xenotransplantation from pigs to humans has been immunological rejections induced by anti- $\alpha$-gal antibodies in humans and $\alpha$-gal epitopes in pigs $(26,27)$. $\alpha$-gal epitopes and their precursors have been identified in all pigs (28). In our study, immunohistochemical analysis revealed that $\alpha$-gal epitopes were not expressed in the porcine DM, which is consistent with several previously published studies (29-32). Hence, porcine DM may have the potential to act as a carrier of tissue-engineered corneal endothelial cells, avoiding the immunological rejections induced by xenotransplantation $\alpha$-gal epitopes, and be immunologically accepted by a human host once implanted in vivo. These results suggest that porcine DM may be as safe as xenotransplantation in terms of immunological response. However, the corneal stroma exhibited greater expression of $\alpha$-gal epitopes in the immunohistochemical study, so the effects of the $\alpha$-gal epitopes on porcine corneal stroma as a tissue-engineered carrier substitute must be considered.

Aside from the risks associated with graft rejections, cross-species transmission of porcine pathogens, particularly PERVs, is also a concern. In light of their differences in the construction of the env genes and their ability to penetrate cells of various organisms, three subtypes were identified: $e n v-A$, $e n v-B$ and $e n v-C$. The sequences of the polymerase genes pol and $g a g$ are conserved in $e n v-A, e n v-B$ and $e n v-C$; thus, they represent the expression of all types of PERVs. It is known that up to 100 integrated proviral copies of PERVs are noted in the pig genome $(16,17,33)$. This number may vary among pig breeds and also within pigs of the same breed (34-38).

In studies of other porcine tissues (e.g., liver, heart, kidney and nerve cells) xenotransplanted to humans, no evidence of PERV expression has been detected; in addition, human serum is reported to have a role of inactivation on PERVs (39-42). These studies suggest the possibility of porcine DM to act as a carrier of tissue-engineered corneal endothelium.

To reduce the risk of infection with PERVs, certain strategies, including antiretroviral therapy (43-45) and the use of RNA interference mechanisms $(46,47)$ have been considered. Moza et al (48) reported in 2001 that complete degradation of PERV DNA was observed following glutaraldehyde (GA) fixation of porcine heart valves, but there were also disadvantages that could induce calcification, inflammation and cytotoxicity. Biological materials treated with epoxy compounds have greater resistance to enzymatic degradation, have reduced cytotoxicity, and are less prone to calcification when compared with GA-fixed heart valves. EDGE is a biofunctional cross-linker with an epoxide structure. Cyganek-Niemiec et al (24) demonstrated that EDGE fixation induces complete degradation of PERV genetic material in porcine aortic heart valves. This study suggests that epoxy compounds may be used in the preparation of bioprosthetic heart valves.

Our PCR results indicated that porcine DM-EDGE could avoid cross-species transmission of PERVs. Thus, it may be possible to increase implantation safety using tissues obtained from pigs. As a result, porcine DM could become an effective xenotransplantation carrier of tissue-engineered endothelium. Previously, it has been reported that anterior chamber-associated immune deviation (ACAID) plays a pivotal role in avoiding herpes simplex virus-1 corneal endotheliitis (49). We considered whether ACAID might play the same role in preventing the potential risk of PERVs in endothelial keratoplasty. It may be possible to use direct porcine endothelial grafts (including porcine DM and porcine endothelium) as a donor endothelium, thus solving the global endothelial donor shortage. Our next study will test the biological compatibility of porcine DM treated with EDGE and evaluate the risk of PERV transmission in vivo by endothelial keratoplasty in animal models.

In conclusion, our results demonstrate that porcine DM may be a viable carrier of tissue-engineered corneal endothelium in terms of its structural, immunological and etiological characteristics. Porcine DM could solve the shortage of tissue-engineered corneal endothelium and could also be used as a carrier of tissue-engineered materials for other purposes.

\section{Acknowledgements}

This study was supported by grants from the National Natural Science Foundation of China (no. 31140025 and 31271045).

\section{References}

1. Waring GO III, Bourne WM, Edelhauser HF and Kenyon KR: The corneal endothelium. Normal and pathologic structure and function. Ophthalmology 89: 531-590, 1982.

2. Kaufman HE, Capella JA and Robbins JE: The human corneal endothelium. Am J Ophthalmol 61: 835-841, 1966.

3. Svedbergh B and Bill A: Scanning electron microscopic studies of the corneal endothelium in man and monkeys. Acta Ophthalmol (Copenh) 50: 321-336, 1972.

4. Gagnon MM, Boisjoly HM, Brunette I, Charest M and Amyot M: Corneal endothelial cell density in glaucoma. Cornea 16: 314-318, 1997.

5. Rao GN, Shaw EL, Arthur E and Aquavella JV: Morphological appearance of the healing corneal endothelium. Arch Ophthalmol 96: 2027-2030, 1978.

6. Engelmann K, Bednarz J and Valtink M: Prospects for endothelial transplantation. Exp Eye Res 78: 573-578, 2004.

7. Ruberti JW and Zieske JD: Prelude to corneal tissue engineering gaining control of collagen organization. Prog Retin Eye Res 27: 549-577, 2008.

8. Chen J, Chen R and Gao S: Morphological characteristics and proliferation of keratocytes cultured under simulated microgravity. Artif Organs 31: 722-731, 2007.

9. Hara $\mathrm{H}$ and Cooper DK: The immunology of corneal xenotransplantation: a review of the literature. Xenotransplantation 17: 338-349, 2010.

10. Kampmeier J, Radt B, Birngruber R and Brinkmann R: Thermal and biomechanical parameters of porcine cornea. Cornea 19: 355-363, 2000.

11. Danielsen CC: Tensile mechanical and creep properties of Descemet's membrane and lens capsule. Exp Eye Res 79: 343-350, 2004.

12. Tanemura M, Ogawa H, Yin DP, Chen ZC, DiSesa VJ and Galili U: Elimination of anti-Gal B cells by alpha-Gal ricin1. Transplantation 73: 1859-1868, 2002. 
13. Tanemura M, Yin D, Chong AS and Galili U: Differential immune responses to $\alpha$-gal epitopes on xenografts and allografts: implications for accommodation in xenotransplantation. J Clin Invest 105: 301-310, 2000.

14. Badylak SF: Xenogeneic extracellular matrix as a scaffold for tissue reconstruction. Transpl Immunol 12: 367-377, 2004.

15. Galili U: The $\alpha$-gal epitope and the anti-gal antibody in xenotransplantation and in cancer immunotherapy. Immunol Cell Biol 83: 674-686, 2005.

16. Lee D, Lee J, Park N, Oh YK, Kwon M and Kim YB: Analysis of natural recombination in porcine endogenous retrovirus envelope genes. J Microbiol Biotechnol 18: 585-590, 2008.

17. Chapman LE, Folks TM, Salomon DR, Patterson AP, Eggerman TE and Noguchi PD: Xenotransplantation and xenogeneic infections. N Engl J Med 333: 1498-1501, 1995.

18. Zarei-Ghanavati S, Khakshoor $\mathrm{H}$ and Zarei-Ghanavati $\mathrm{M}$ Reverse big bubble: a new technique for preparing donor tissue of descemet membrane endothelial keratoplasty. Br J Ophthalmol 94: 1110-1111, 2010.

19. Gonzalez-Andrades M, de la Cruz Cardona J, Ionescu AM, Campos A, del Mar Perez M and Alaminos M: Generation of bioengineered corneas with decellularized xenografts and human keratocytes. Invest Ophthalmol Vis Sci 52: 215-222, 2011.

20. Bösch S, Arnauld C and Jestin A: Study of full-length porcine endogenous retrovirus genomes with envelope gene polymorphism in a specific-pathogen-free large white swine herd. J Virol 74: 8575-8581, 2000.

21. Le Tissier P, Stoye JP, Takeuchi Y, Patience C and Weiss RA: Two sets of human-tropic pig retrovirus. Nature 389: 681-682, 1997.

22. Wang Y, Ren J, Lan L, et al: Characterization of polymorphisms of transferrin receptor and their association with susceptibility to ETEC F4ab/ac in pigs. J Anim Breed Genet 124: 225-229, 2007.

23. Livak KJ and Schmittgen TD: Analysis of relative gene expression data using real-time quantitative PCR and the 2(-Delta Delta C(T)) Method. Methods 25: 402-408, 2001.

24. Cyganek-Niemiec A, Strzalka-Mrozik B, Pawlus-Lachecka L, et al: Degradation effect of diepoxide fixation on porcine endogenous retrovirus DNA in heart valves: molecular aspects. Int J Artif Organs 35: 25-33, 2012.

25. Schultz RO, Matsuda M, Yec RW, et al: Corneal endothelial changes in type I and type II diabetes mellitus. Am J Ophthalmol 98: 401-410, 1984.

26. Grönlund H, Adédoyin J, Commins SP, Platts-Mills TA and van Hage M: The carbohydrate galactose-alpha-1, 3-galactose is a major IgE-binding epitope on cat $\operatorname{IgA}$. J Allergy Clin Immunol 123: 1189-1191, 2009.

27. Galili U: Evolution and pathophysiology of the human natural anti- $\alpha$-galactosyl IgG (anti-gal) antibody. Springer Semin Immunopathol 15: 155-171, 1993.

28. Oriol R, Barthod F, Bergemer AM, Ye Y, Koren E and Cooper DK: Monomorphic and polymorphic carbohydrate antigens on pig tissues: implications for organ xenotransplantation in the pig-to-human model. Transpl Int 7: 405-413, 1994.

29. Amano S: Transplantation of cultured human corneal endothelial cells. Cornea 22 (Suppl 7): S66-S74, 2003.

30. Goldstein IJ and Winter HG: The Griffonia simplicifolia I-B4 isolectin. A probe for alpha-D-galactosyl end groups. Subcell Biochem 32: 127-141, 1999.

31. Wood C, Kabat EA, Murphy LA and Goldstein IJ: Immunochemical studies of the combining sites of the two isolectins, A4 and B4, isolated from Bandeiraea simplicifolia. Arch Biochem Biophys 198: 1-11, 1979.
32. Tempel W, Tschampel S and Woods RJ: The xenograft antigen bound to griffonia simplicifolia lectin 1-B4. X-ray crystal structure of the complex and molecular dynamics characterization of the binding site. J Biol Chem 277: 6615-6621, 2002.

33. Amano S, Shimomura N, Kaji Y, Ishii K, Yamagami S and Araie M: Antigenicity of porcine cornea as xenograft. Curr Eye Res 26: 313-318, 2003.

34. Ma Y, Yang Y, Lv M, et al: Real-time quantitative polymerase chain reaction with SYBR green i detection for estimating copy numbers of porcine endogenous retrovirus from Chinese miniature pigs. Transplant Proc 42: 1949-1952, 2010.

35. Garkavenko O, Wynyard S, Nathu D, et al: Porcine endogenous retrovirus (PERV) and its transmission characteristics: a study of the New Zealand designated pathogen-free herd. Cell Transplant 17: 1381-1388, 2008.

36. Mang R, Maas J, Chen X, Goudsmit J and van Der Kuyl AC: Identification of a novel type $\mathrm{C}$ porcine endogenous retrovirus: evidence that copy number of endogenous retroviruses increases during host inbreeding. J Gen Virol 82: 1829-1834, 2001.

37. Akiyoshi DE, Denaro M, Zhu H, Greenstein JL, Banerjee P and Fishman JA: Identification of a full-length cDNA for an endogenous retrovirus of miniature swine. J Virol 72: 4503-4507, 1998.

38. Garkavenko O, Wynyard S, Nathu D, et al: Porcine endogenous retrovirus transmission characteristics from a designated pathogen-free herd. Transplant Proc 40: 590-593, 2008.

39. Pitkin Zand Mullon C: Evidence of absence of porcine endogenous retrovirus (PERV) infection in patients treated with a bioartificial liver support system. Artif Organs 23: 829-833, 1999.

40. Martin U, Steinhoff G, Kiessig V, et al: Porcine endogenous retrovirus (PERV) was not transmitted from transplanted porcine endothelial cells to baboons in vivo. Transpl Int 11: 247-251, 1998.

41. Heneine W, Tibell A, Switzer WM, et al: No evidence of infection with porcine endogenous retrovirus in recipients of porcine islet-cell xenografts. Lancet 352: 695-698, 1998.

42. Paradis K, Langford G, Long Z, et al: Search for cross-species transmission of porcine endogenous retrovirus in patients treated with living pig tissue The XEN 111 Study Group. Science 285: 1236-1241, 1999.

43. Kaulitz D, Fiebig U, Eschricht M, Wurzbacher C, Kurth R and Denner J: Generation of neutralising antibodies against porcine endogenous retroviruses (PERVs). Virology 411: 78-86, 2011.

44. Fiebig U, Stephan O, Kurth R and Denner J: Neutralizing antibodies against conserved domains of p15E of porcine endogenous retroviruses: basis for a vaccine for xenotransplantation? Virology 307: 406-413, 2003.

45. Qari SH, Magre S, García-Lerma JG, et al: Susceptibility of the porcine endogenous retrovirus to reverse transcriptase and protease inhibitors. J Virol 75: 1048-1053, 2001.

46. Ramsoondar J, Vaught T, Ball S, et al: Production of transgenic pigs that express porcine endogenous retrovirus small interfering RNAs. Xenotransplantation 16: 164-180, 2009.

47. Dieckhoff B, Petersen B, Kues WA, Kurth R, Niemann H and Denner J: Knockdown of porcine endogenous retrovirus (PERV) expression by PERV-specific shRNA in transgenic pigs. Xenotransplantation 15: 36-45, 2008.

48. Moza AK, Mertsching H, Herden T, Bader A and Haverich A: Heart valves from pigs and the porcine endogenous retrovirus: experimental and clinical data to assess the probability of porcine endogenous retrovirus infection in human subjects. J Thorac Cardiovasc Surg 121: 697-701, 2001.

49. Zheng X, Yamaguchi M, Goto T, Okamoto S and Ohashi Y: Experimental corneal endotheliitis in rabbit. Invest Ophthalmol Vis Sci 41: 377-385, 2000. 